\title{
Pemanfaatan Teknologi Informasi dan Komunikasi (TIK) oleh UMKM pada Masa Pandemi COVID-19
}

\author{
Utilization of Information and Communication Technology (ICT) by MSMEs during the COVID-19 \\ Pandemic \\ Eka Handayani a," ,Putri Pradnyawidya Sari ${ }^{\mathrm{a}, \mathrm{b}}$, Maulia Jayantina Islami a,c \\ ${ }^{a}$ Balai Pengembangan SDM dan Penelitian (BPSDMP) Kominfo Surabaya, Jawa Timur, Indonesia \\ email: "ekah001@kominfo.go.id, butripradnya@gmail.com, 'maul005@kominfo.go.id
} Menerima 20 Desember 2021, Revisi 23 Desember 2021, Diterima 27 Desember 2021, Online 27 Desember 2021

\begin{abstract}
ABSTRAK
Kebiasaan baru selama masa covid 19 tidak hanya mengubah cara hidup masyarakat tetapi juga merombak strategi bisnis dunia usaha. Sepinya dagangan dan turunnya omset membuat UMKM harus berinovasi. Pemanfaatan teknologi adalah sesuatu yang tidak dapat dihindari lagi. Tujuan dari kajian ini adalah memberikan gambaran bagaimana UMKM beradaptasi untuk bertahan di masa pandemi ini, serta untuk mengkaji bagaimana pemanfaatan teknologi digital oleh UMKM sehingga mereka harus mengalami perubahan dari bisnis konvensional menjadi bisnis secara online. Penelitian ini menggunakan teknik analisis data deskriptif dengan tujuan untuk memberikan data tentang informasi yang di perlukan dalam pengamatan. Langkah prosedur dalam analisis data adalah dengan cara reduksi data, penyajian data, dan pengambilan kesimpulan. Data diolah dengan aplikasi Ms. Excel 2013 untuk mendapat persentase sehingga memperoleh insight untuk di analisis. Data diperoleh dari survei online menggunakan tools dari google form. Banyaknya responden yang memilih strategi dengan memanfaatkan teknologi informasi maka peran pemerintah adalah dengan memberi dukungan berupa bimbingan dan mentoring usaha khususnya di bidang teknologi informasi, baik berupa pelatihan maupun bimbingan teknis. Secara infrastruktur pemerintah dapat memberikan memberi dukungan pemasaran dan kanal distribusi bagi produk mereka. Pelatihan yang mereka butuhkan dapat berupa pelatihan pemasaran digital, pelatihan produksi dan pelatihan pengelolaan keuangan. Dengan pelatihan tersebut maka akan mengakselerasi digital bagi pelaku UMKM karena menerapkan pola pikir.

Kata kunci : UMKM, Strategi, Pandemi, TIK.
\end{abstract}

\section{ABSTRACT}

New habits during the COVID-19 period have not only changed the way people live, but also overhauled the business strategy of the business world. The lack of merchandise and the decline in turnover have forced MSMEs to innovate. Utilization of technology is something that can not be avoided anymore. The purpose of this study is to provide an overview of how MSMEs adapt to survive during this pandemic, as well as to examine how MSMEs use digital technology so that they have to change from a conventional business to an online business. This study uses descriptive data analysis techniques with the aim of providing data about the information needed for observation. The procedure steps in data analysis are data reduction, data presentation, and conclusion drawing. The data is processed with the Ms. application. Excel 2013 to get percentages so that you get insights for analysis. The data was obtained from an online survey using tools from google form. The large number of respondents who choose a strategy by utilizing information technology, the government's role is to provide support in the form of business guidance and mentoring, especially in the field of information technology, both in the form of training and technical guidance. In terms of infrastructure, the government can provide marketing support and distribution channels for their products. The training they need can be in the form of digital marketing training, production training and financial management training. With this training, it will accelerate digital for MSME actors because they apply the mindset

Keyword: MSMEs, Strategy, Pandemic, ICT. 


\section{PENDAHULUAN}

Kebiasaan baru selama masa covid 19 tidak hanya mengubah cara hidup masyarakat tetapi juga merombak strategi bisnis dunia usaha. Pandemi covid 19 membuat sektor ekonomi di Indonesia terpukul banyak pelaku usaha kecil dan menengah (UMKM) susah payah menghadapi bisnisnya yang terhambat. Namun sebagian dari mereka mampu tetap bertahan dengan memanfaatkan sedikit peluang yang ada. Efek pandemi yang begitu signifikan mempengaruhi model dan rantai produksi baik proses distribusi maupun ketersediaan produk. Pemberlakuan Pembatasan Sosial Berskala Besar (PSBB) yang kemudian di lanjutkan dengan Pemberlakuan Pembatasan Kegiatan Masyarakat (PPKM) di beberapa wilayah juga berimbas pada operasional usaha.

Korban utama dari wabah COVID-19 adalah UMKM khususnya dinegara berkembang yang disebabkan karena terbatasnya penggunaan teknologi digital (Chunguang Bai, 2021). Menurut data Badan Pusat Statistik (BPS) dampak pandemi terhadap pendapatan perusahaan berbeda sesuai dengan skala usahanya, namun secara keseluruhan $82,85 \%$ perusahaan mengalami penurunan pendapatan, $14,60 \%$ pendapatan tetap dan hanya 2,55\% mengalami kenaikan. Secara umum 8 dari setiap 10 perusahaan cenderung mengalami penurunan pendapatan (Badan Pusat Statistik, 2020). Dampak pandemi terhadap UMKM tidak hanya di Indonesia namun hampir di seluruh belahan dunia. Di Amerika Serikat usaha yang terkena dampak adalah restoran dan hotel, begitu juga dengan usaha kecil lainnya seperti layanan pendidikkan, kesehatan dan usaha privat social. Banyak sektor seperti layanan pendidikan swasta, pusat pendidikan anak-anak, kelas olahraga, sekolah seni dimana semua sektor yang membutuhkan jarak fisik adalah yang terkena dampaknya. Bahkan seperempat usaha kecil dimungkinkan tutup secara permanen (Dua et al., 2020).

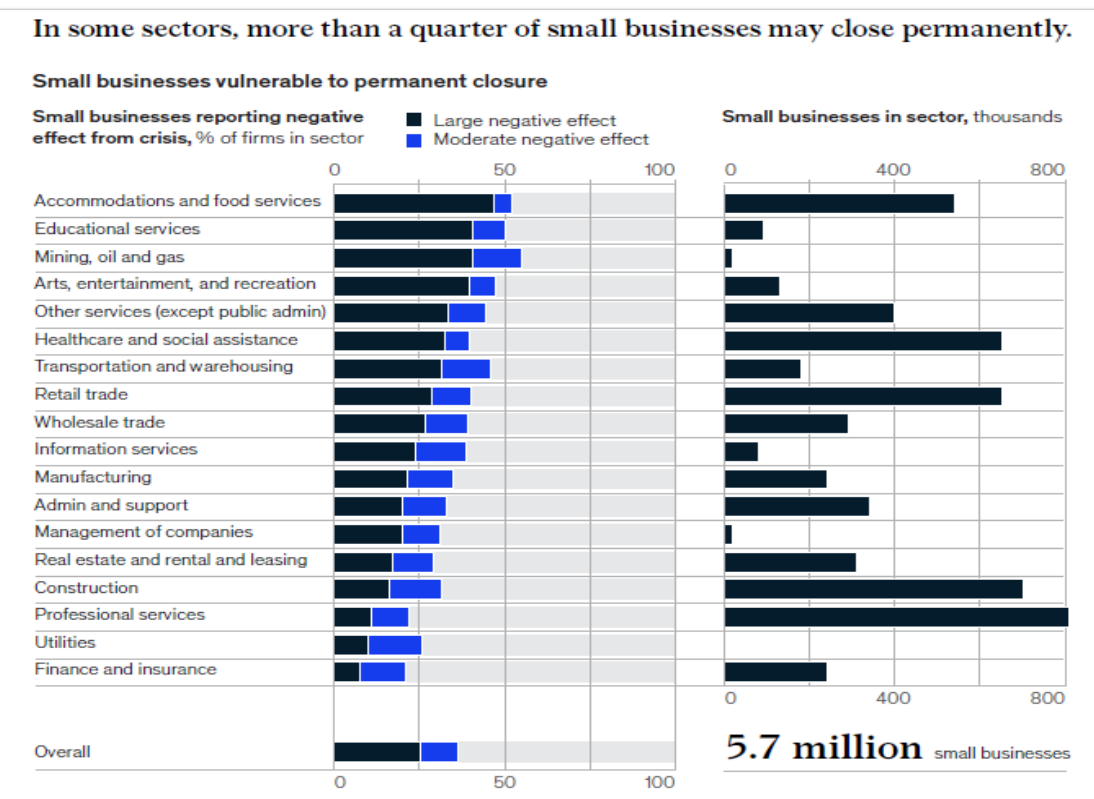

Gambar 1. Riset Mckinsey sektor usaha kecil yang terkena efek negatif dari pandemi (Dua et al., 2020)

Riset Mckinsey pada gambar 1 mewakili dampak yang terjadi terhadap usaha kecil di seluruh dunia, terlihat bahwa sektor akomodasi dan makanan serta layanan pendidikan terpengaruh oleh perubahan perilaku pelanggan, khususnya yang menggunakan jarak fisik dan operasional karena adanya pembatasan selama pandemi. Usaha kecil tersebut dimungkinkan mengalami penutupan secara permanen karena sudah memiliki resiko secara financial bahkan sebelum adanya krisis dimasa pandemi ini. Didalam penelitian terbaru dari Federal Reserve menemukan bahwa hanya 35\% usaha kecil yang masih sehat dipenghujung tahun 2019 (FRBNY, 2020), sehingga yang kurang sehat akan tiga kali lebih dimungkinkan tutup secara permanen atau menjual asetnya sebagai bentuk respon terhadap krisis ini.

Sepi nya dagangan dan turunnya omset membuat UMKM harus berinovasi. Pemanfaatan teknologi adalah sesuatu yang tidak dapat dihindari lagi. Pelaku usaha beradaptasi dengan merubah strategi pemasaran ke pemasaran digital supaya dapat bertahan di era pandemi, sehingga UMKM pun bertransformasi ke bisnis online

114 | Vol.10 No.2 /November 2021 http://doi.org/10.31504/komunika.v10i2.4622.

(c) 2021 Jurnal Komunika:Jurnal Komunikasi dan Informatika. Semua hak cipta dilindungi undang-undang. 
sebagai pengganti keterbatasan manusia di era pandemi. UMKM yang dapat bertahan adalah mereka yang dapat menyesuaikan diri dengan keadaan pandemi kemudian membuat perencanaan dan melakukan prosedur baru dalam bekerja (Santoso, 2020).

Tujuan dari kajian ini adalah memberikan gambaran bagaimana UMKM beradaptasi untuk bertahan di masa pandemi ini, serta untuk mengkaji bagaimana pemanfaatan teknologi digital oleh UMKM sehingga mereka harus mengalami perubahan dari bisnis konvensional menjadi bisnis secara online.

\section{KAJIAN PUSTAKA}

Pada penelitian yang berjudul "Review of Digital Marketing \& Business Sustainability of E-Commerce During Pandemic Covid19 In Indonesia" mengkaji strategi yang digunakan oleh UMKM dalam rangka bertahan dan tumbuh kembali di masa pandemi Covid19. Metode yang digunakan adalah studi Pustaka /literature. Dari penelitian ini terungkap bahwa di masa pandemi konsumen nyaris lupa dengan merek, maka komunikasi melalui iklan digital akan meningkatkan kembali brand awareness. Perilaku digital mendorong perluasan konsumen online bukan lagi pada generasi milenial. Beberapa UMKM telah mengalami bangkrut. Namun tidak sedikit yang akhirnya bangkit dan kemudian bertumbuh. UMKM mengubah operasional produksi dengan mengurangi jumlah produksi dan sekaligus melakukan inovasi untuk menambah daya saing. Di sisi lain penggunaan digital marketing secara massif telah dilakukan untuk meningkatkan awareness pelanggan. Marketplace sebagai bentuk manifestasi dari e-commerce digunakan sebagai inovasi atau perubahan metode penjualan (Santoso, 2020).

Kajian berjudul "Transformasi UMKM dari Bisnis Konvensional Menjadi Bisnis Online Berbasis Digital di Masa Pandemi COVID-19" bertujuan untuk mengetahui transformasi UMKM dari bisnis konvensional menjadi bisnis online berbasis digital di masa pandemi COVID-19. Kajian ini menggunakan metode deskriptif kualitatif. Informasi digabungkan dan dipecah menggunakan pendekatan pengujian yang jelas yang menghubungkan elemen-elemen tertentu dengan fenomena empirik yang terjadi saat ini. Temuan kajian ini menunjukkan bahwa pelaku UMKM memiliki kesempatan untuk mentransformasikan usahanya menjadi bisnis online berbasis digital dengan tujuan agar mereka dapat menjangkau pemasaran yang lebih luas karena dilakukan secara online (Sahanaya, 2021).

Penelitian "The Influence of The Covid-19 Pandemic Against The Impact Of Digital Economy Implementation on MSMES" bertujuan untuk mengetahui sejauh mana pengaruh pandemi Covid-19 terhadap dampak implementasi ekonomi digital pada UMKM. Apakah implementasi ekonomi digital pada UMKM dapat menjadi salah satu alternatif untuk menghadapi kondisi tersebut? Implementasi Ekonomi Digital pada penelitian ini berupa pemanfaatan TIK dalam bentuk Digital Capital yang merupakan akumulasi pemanfaatan kopetensi digital dengan teknologi digital. Penelitian ini menggunakan analisis regresi linear berganda dengan bantuan Software StataMP 15. Hasil Penelitian ini menunjukan bahwa implementasi ekonomi digital berupa pemanfaatan TIK dalam bentuk Digital Capital berpengaruh signifikan terhadap pendapatan UMKM serta tidak terpengaruh oleh pandemic Covid-19 yang terjadi (Rahmadan et al., 2021).

Merujuk pada penelitian sebelumnya maka kebaruan dari penelitian ini adalah menggambarkan bagaimana usaha dari pelaku UMKM dalam beradaptasi di masa pandemi. Melalui metode survei online maka dapat dianalisis siapa saja yang berperan didalam mengatasi dampak pandemi terhadap UMKM serta bagaimana peran pemerintah dalam membantu UMKM mengatasi kesulitan tersebut. Apakah benar bahwa pemanfaatan teknologi adalah satu-satunya jalan keluar usaha kecil untuk bertahan dimasa pandemi ini. Dengan menggunakan variabel dari transformasi digital maka dapat dilihat variabel "digital culture" dapat mempengaruhi sustainability UMKM.

\section{METODE PENELITIAN}

Sebanyak 193 responden berpartisipasi pada survey ini dengan metode pemilihan sampling Non Probability Sampling yaitu peneliti melakukan pengiriman link survey kepada jaringan, perkumpulan, gabungan pelaku usaha di Jawa Timur. Tujuannya adalah untuk mendapatkan gambaran secara utuh mengenai pelaku usaha yang memenuhi keterwakilan (representativeness). Cakupan responden yaitu semua lapangan usaha, usaha rumah

115 | Vol.10 No.2 /November 2021 http://doi.org/10.31504/komunika.v10i2.4622.

(c) 2021 Jurnal Komunika:Jurnal Komunikasi dan Informatika. Semua hak cipta dilindungi undang-undang. 
tangga, serta peserta pelatihan marketing digital. Waktu pelaksanaan yaitu tanggal 11 Mei 2020 sampai dengan 12 September 2021. Adapun profil responden pada kajian ini dapat dilihat pada gambar 2 dan gambar 3.
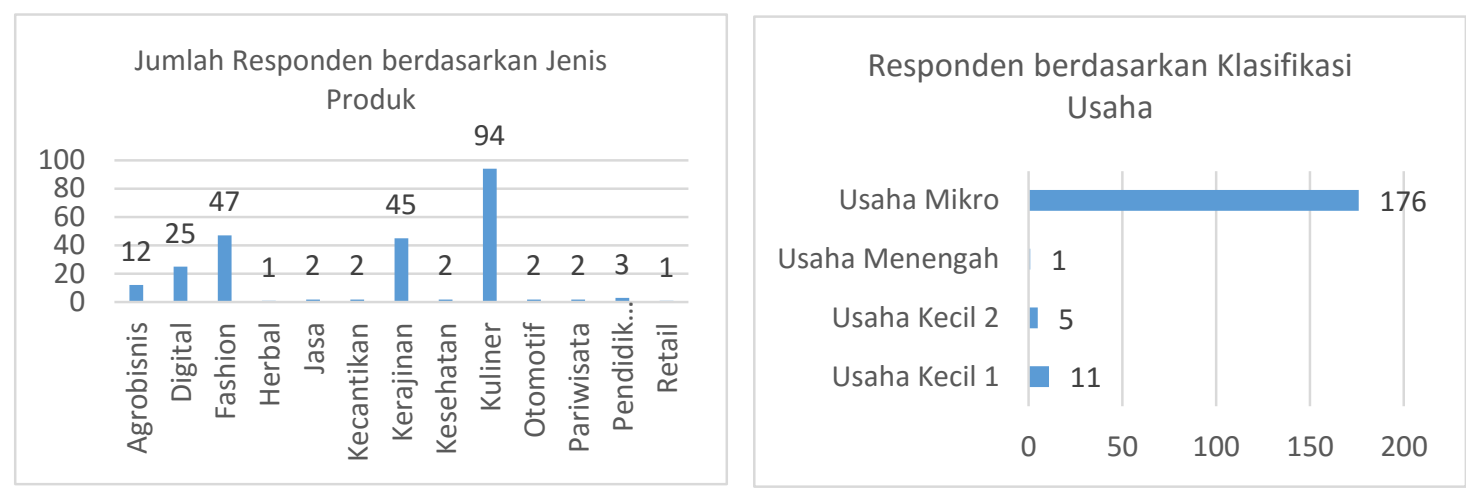

Gambar 2. Jumlah Responden Berdasarkan Jenis Produk dan Klasifikasi Usaha (Data Primer yang diolah, 2021)

Jumlah responden berdasarkan jenis produk terdiri dari produk Agrobisnis, Digital, Fashion, Herbal, Jasa, Kecantikan, Kerajinan, Kesehatan, Kuliner, Otooomotif, Pariwisata dan Retail. Sedangkan jumlah responden berdasarkan klasifikasi usaha terdiri dari usaha mikro yaitu dengan omzet antara 0-300 jutaper tahun, usaha menengah omzet antara 2,5 milyar - 4,5 milyar per tahun, usaha kecil 1 dengan omzet antara 300juta-500 juta per tahun dan usaha kecil 2 dengan omzet antara 500 juta-1milyar per tahun. Karakter responden terbanyak adalah usaha mikro dibidang kuliner.

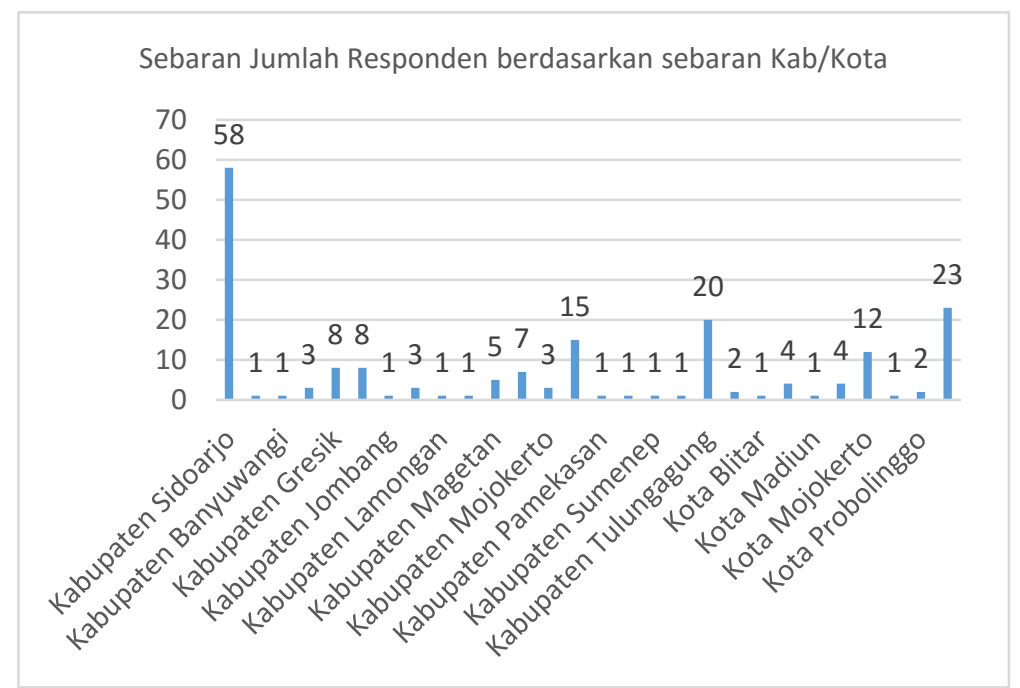

Gambar 3. Jumlah Responden Berdasarkan sebaran Kab/Kota (Data Primer yang diolah, 2021)

Responden berasal dari kabupaten Sidoarjo, Banyuwangi, Gresik, Jombang, Lamongan, Magetan, Mojokerto, Pamekasan, Sumenep, Tulungagung, Kota Blitar, Madiun, Mojokerto dan Probolinggo. Responden terbanyak berasal dari Kabupaten Sidoarjo.

Penelitian ini menggunakan teknik analisis data deskriptif dengan tujuan untuk memberikan data tentang informasi yang di perlukan dalam pengamatan. Langkah prosedur dalam analisis data adalah dengan cara reduksi data, penyajian data, dan pengambilan kesimpulan. Data diolah dengan aplikasi Ms. Excel 2013 untuk mendapat persentase sehingga memperoleh insight untuk di analisis. Data diperoleh dari survei online menggunakan tools dari google form.

\section{ANALISIS DAN PEMBAHASAN}

Masa pandemi mempengaruhi akselerasi digital di masyarakat khususnya pelaku usaha. Hal ini memperngaruhi gaya berjualan sehingga menimnbulkan strategi baru dalam berbisnis. Pada akhirnya terdapat kebiasaan baru dalam melakukan transaksi bisnis, seperti berbelanja online, pembayaran secara digital, etalase produk di media sosial dan lain sebagainya. Pembentukan masyarakat yang secara digital tersebut menimbulkan

116 | Vol.10 No.2 /November 2021 http://doi.org/10.31504/komunika.v10i2.4622.

(c) 2021 Jurnal Komunika:Jurnal Komunikasi dan Informatika. Semua hak cipta dilindungi undang-undang. 
kebiasaan baru sehingga menjadi budaya digital atau digital culture. Digital culture merupakan syarat melakukan transformasi digital karena menerapkan budaya digital berarti mengubah pola pikir (mindset) supaya dapat beradaptasi dengan perkembangan digital. Pada bab ini akan dianalisis bagaimana digital culture masyarakat khususnya pelaku usaha sebelum pandemi dan dimasa pandemi.

\section{Pemanfaatan TIK sebelum pandemi}

Sebagian besar pelaku usaha sudah memanfaatkan TIK sebelum pandemi untuk menjalankan usahanya dapat terlihat pada gambar 4. Hal tersebut dikarenakan hadirnya media sosial sudah dirasakan cukup efektif sebagai alat pengembangan UMKM khususnya pemasaran jauh sebelum pandemi. Pemanfaatan media sosial sebelum masa pandemi dapat dilihat pada gambar 5 dimana UMKM memanfaatkan TIK dengan memasarkan produknya melalui media sosial sebanyak 69,4\%. Media sosial yang dimanfaatkan seperti facebook, instagram dll. Pemanfaatan TIK yang kedua yaitu memasarkan produk melalui online messaging yaitu sebanyak 66,8\%. Sedangkan UMKM yang memasarkan produknya dengan cara konvensional sebanyak 61,1\%. Pemanfaatan marketplace seperti shopee, bukalapak, tokopedia dan lain-lain hanya 36,3\%.

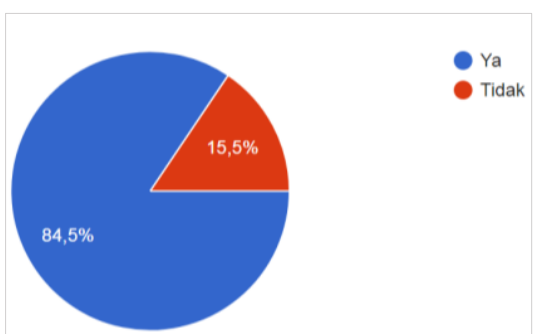

Gambar 4. UMKM yang sudah memanfaatkan TIK sebelum pandemi (Data Primer yang diolah, 2021)

Sebelum masa pandemi UMKM sudah banyak yang menggunakan media sosial untuk memasarkan produknya. Hal ini membuktikan bahwa budaya digital sudah ada di masa sebelum pandemi. Menurut penelitian (Hani Atun Mumtahana, 2017) menjelaskan bahwa pemanfaatan teknologi e-commerce dapat berdampak pada peningkatan pendapatan UMKM sebanyak 15\%. Karena pengaruh positif tersebut maka UMKM sudah memanfaatkan TIK sebelum pandemi. Tidak hanya pada pelaku usaha pemanfaatan TIK juga mampu menarik banyak konsumen di Indonesia sebelum pandemi.

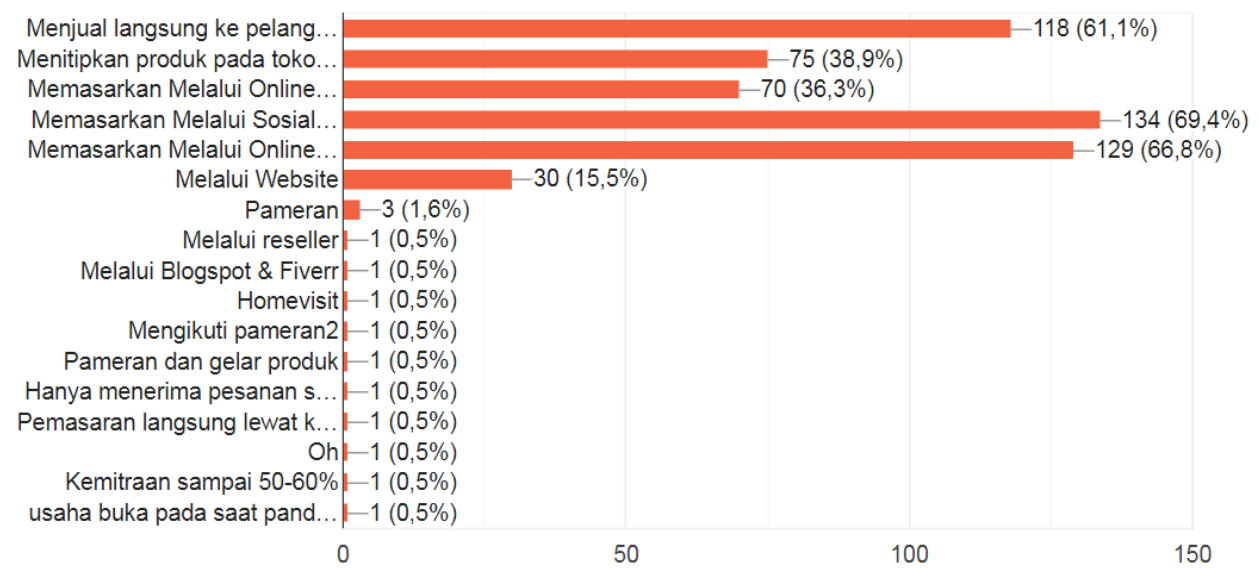

Gambar 5. Pemasaran produk sebelum pandemi (Data Primer yang diolah, 2021)

Transformasi digital membutuhkan redefinisi pemikiran, proses, dan keterampilan di dunia digital. Transformasi digital paling sukses adalah menanamkan pengembangan dan kolaborasi ke model bisnisnya dan mendorong perubahan mendasar dalam pengolahan data dan pengelolaan karyawan. Keberhasilan tersebut dengan melakukan transisi menjadi "usaha digital based" dan menanamkan "budaya inovasi". Hal tersebut sudah dilakukan oleh UMKM dengan memanfaatkan TIK di pengelolaan bisnisnya. Termasuk pengelolaan keuangan, pemasaran dan pengolahan data pelanggan. Hal ini dapat terlihat pada gambar 6 dimana responden terbanyak memanfaatkan TIK untuk pemasaran yaitu $96,3 \%$. Memanfaatkan teknologi sebagai sistem pembayaran (e-payment system) yaitu sebanyak 35\%. Serta memanfaatkan TIK sebagai Business Intelligence yaitu pengelolaan informasi penting untuk pengembangan

117 | Vol.10 No.2 /November 2021 http://doi.org/10.31504/komunika.v10i2.4622.

(C) 2021 Jurnal Komunika:Jurnal Komunikasi dan Informatika. Semua hak cipta dilindungi undang-undang. 
bisnis yaitu sebanyak 33,1\%. Sebanyak 30,1\% pemanfaatan TIK untuk mengolah data pelanggan. Sisanya pemanfaatan teknologi sebagai produksi, promo dan edukasi, promosi serta kelas online.

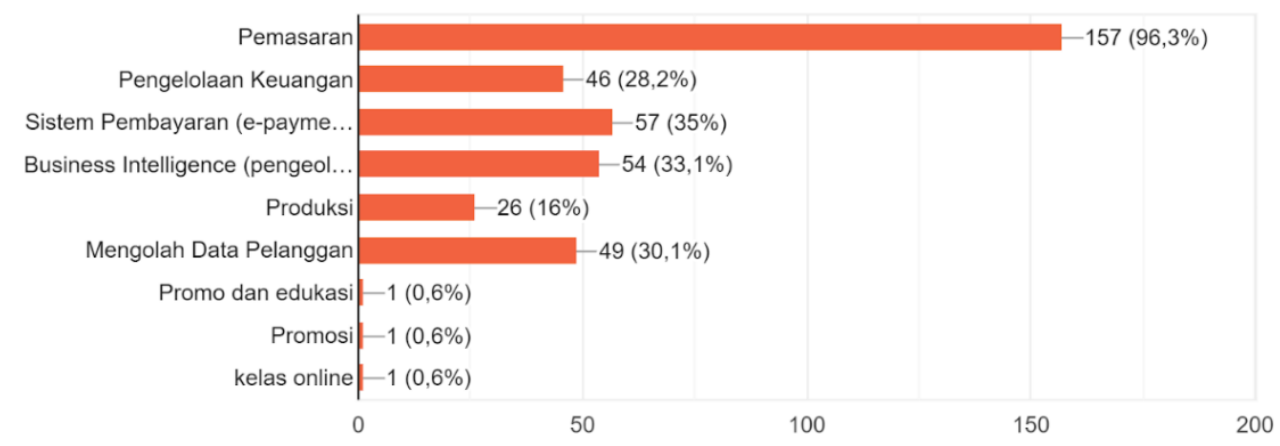

Gambar 6. Pemanfaatan Teknologi Informasi dan Komunikasi pada Usaha (Data Primer yang diolah, 2021)

\section{Pemanfaatan TIK pada masa pandemi}

Pada masa pandemi pengguna media sosial terus meningkat seiring dengan diberlakukannya Pembatasan Sosial Berskala Besar (PSBB) dan Pemberlakuan Pembatasan Kegiatan Masyarakat (PPKM) membuat masyarakat melakukan kegiatan secara online. Peningkatan dalam penggunaan media sosial dapat terlihat pada gambar 7 dimana terdapat peningkatan penggunaan media sosial dari sebelum pandemi dan di masa pandemi. Dimasa pandemi UMKM yang memanfaatkan media sosial naik menjadi $75,6 \%$ dari yang sebelumnya yaitu $69,4 \%$ dapat terlihat pada gambar 7. Online messaging menjadi alat yang paling banyak dimanfaatkan oleh pelaku UMKM untuk memasarkan produknya yaitu sebanyak 77,7\%, disusul kemudian oleh pemanfaatan marketplace yaitu sebesar $42 \%$. Namun masih ada juga yang tidak memanfaatkan TIK yaitu masih menggunakan toko konvensional sebagai pemasarannya. Sebesar $36,8 \%$ pelaku usaha masih menggunakan toko offline untuk menjual produknya.

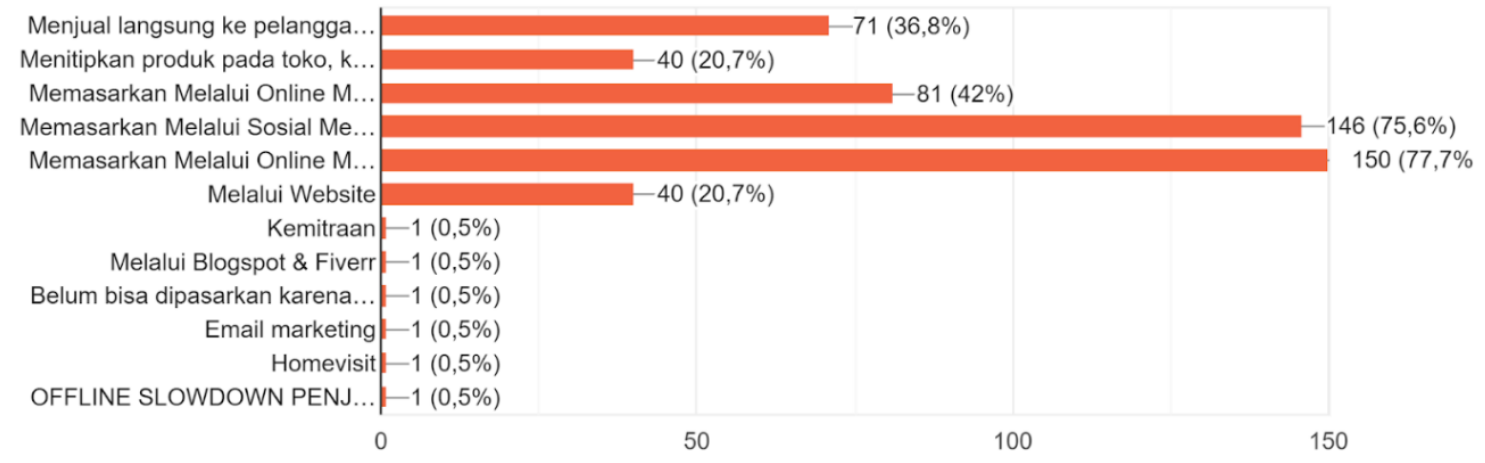

Gambar 7. Pemasaran Produk dimasa Pandemi (Data Primer yang diolah, 2021)

Beberapa usaha mampu bertahan, namun tidak sedikit juga yang akhirnya mengalami gulung tikar. Dalam masa bertahan ini diperlukan strategi untuk memasarkan produk UMKM. Beberapa strategi yang sudah dilakukan oleh UMKM demi keberlangsungan usahanya dapat dilihat pada gambar 8. Responden yang memilih untuk menggunakan strategi dengan memanfaatkan teknologi informasi sebagai pemasaran produk mereka sebanyak $88,6 \%$. Strategi kedua yang dipilih oleh responden yaitu melakukan penyesuaian fungsi dan jam kerja yaitu sebanyak $26,4 \%$. Sebanyak $11,4 \%$ responden memilih strategi merumahkan karyawan dengan memotong pembayaran. Ada juga yang memilih strategi dengan melakukan Pemutusan Hubungan Kerja (PHK) sebagian karyawan sebanyak $9,8 \%$.

\section{KESIMPULAN}

Banyaknya responden yang memilih strategi dengan memanfaatkan teknologi informasi maka peran pemerintah adalah dengan memberi dukungan berupa bimbingan dan mentoring usaha khususnya di bidang teknologi informasi, baik berupa pelatihan maupun bimbingan teknis. Secara infrastruktur pemerintah dapat memberikan memberi dukungan pemasaran dan kanal distribusi bagi produk mereka. Pelatihan yang mereka

118 | Vol.10 No.2 /November 2021 http://doi.org/10.31504/komunika.v10i2.4622.

(c) 2021 Jurnal Komunika:Jurnal Komunikasi dan Informatika. Semua hak cipta dilindungi undang-undang. 
butuhkan dapat berupa pelatihan pemasaran digital, pelatihan produksi dan pelatihan pengelolaan keuangan. Dengan pelatihan tersebut maka akan mengakselerasi digital bagi pelaku UMKM karena menerapkan pola pikir dan budaya digital. Dibutuhkan sinergitas antara pihak pemerintah dan lembaga keuangan untuk bersatu mengangkat UMKM dimasa pandemi ini.

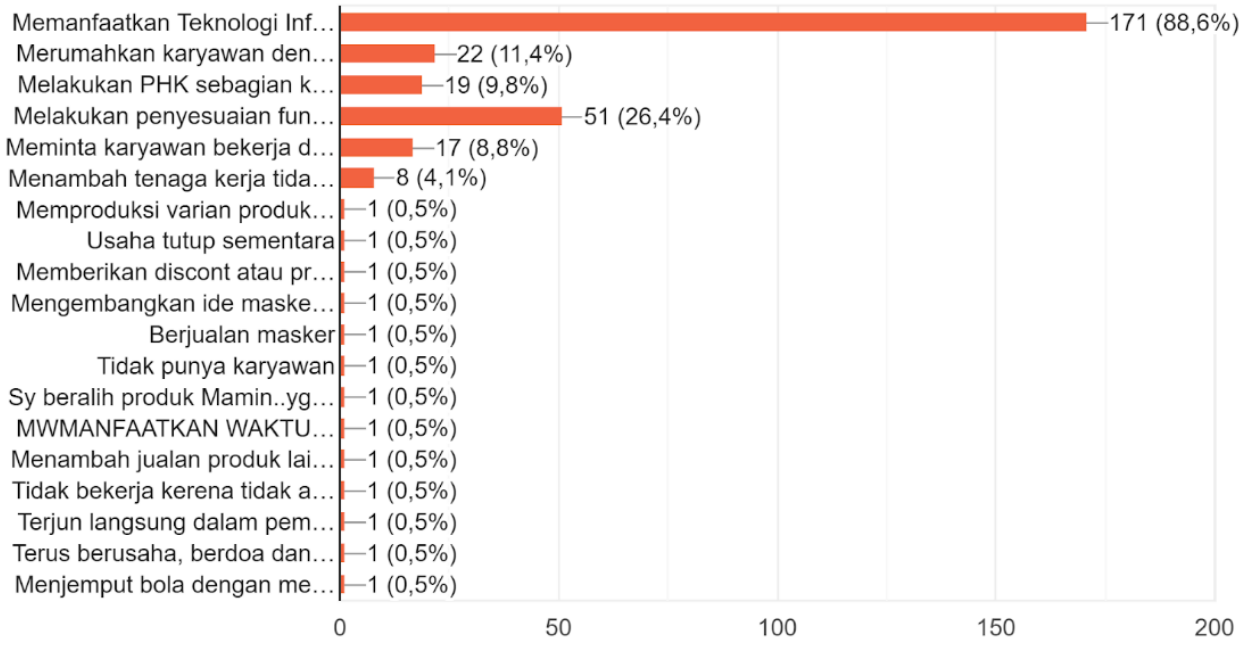

Gambar 9. Strategi yang di tempuh untuk mempertahankan kelangsungan usaha disituasi pandemi COVID-19 (Data Primer yang diolah, 2021)

\section{DAFTAR PUSTAKA}

Badan Pusat Statistik. (2020). Katalog: 3101028. Analisis Hasil Survei Dampak COVID-19 Terhadap Pelaku Usaha, vi+ 22 halaman.

Dua, A., Ellingrud, K., Mahajan, D., \& Silberg, J. (2020). Social Sector Practice: Which Small Busnisses are Most Vulnerabel to Covid-19 -- and When. June.

FRBNY. (2020). Can small firms weather the economic effects of COVID-19? Federal Reserve Bank of New York, April, 3. https://www.fedsmallbusiness.org/medialibrary/fedsmallbusiness/files/2019/20191211-cedminority-owned-firms-report.pdf.

Rahmadan, R., Indrawari, I., \& Ridwan, E. (2021). Pengaruh Pandemi Covid-19 Terhadap Dampak Implementasi Ekonomi Digital Pada Umkm. Menara Ilmu, 15(1), 84-96. https://doi.org/10.31869/mi.v15i1.2384

Sahanaya, G. A. (2021). Digital Generation For Digital Nation. Proceeding Seminar Nasional Teknologi Pendidikan, $1,144-154$.

Santoso, R. (2020). Review of Digital Marketing \& Business Sustainability of E-Commerce During Pandemic Covid19 In Indonesia. Jurnal Ilmu Ekonomi Terapan, 5(2), 36-48. 